\title{
Dryness Indices Based on Remotely Sensed Vegetation and Land Surface Temperature for Evaluating the Soil Moisture Status in Cropland-Forest-Dominant Watersheds
}

\author{
Heewon Moon ${ }^{1}$ and Minha Choi ${ }^{2, *}$ \\ ${ }^{1}$ Department of Civil, Architectural and Environmental System Engineering, Sungkyunkwan University, Suwon, Gyeonggi-do, \\ Korea \\ ${ }^{2}$ Department of Water Resources, Graduate School of Water Resources, Sungkyunkwan University, Suwon, Gyeonggi-do, Korea
}

Received 27 November 2014, revised 18 April 2015, accepted 22 April 2015

\begin{abstract}
The Temperature Vegetation Dryness Index (TVDI) was derived from the relationship between remotely sensed vegetation indices and land surface temperature $\left(\mathrm{T}_{\mathrm{S}}\right)$ in this study for assessing the soil moisture status at regional scale in South Korea. The Leaf Area Index (LAI) is newly applied in this method to overcome the increasing uncertainty of using the Normalized Difference Vegetation Index (NDVI) at high vegetation conditions. Both dryness indices were found to be well correlated with in situ soil moisture and 8-day average precipitation at most of the in situ measurement sites. The dryness indices accuracy was found to be influenced by rainfall events. An average correlation coefficient was improved from -0.253 to -0.329 when LAI was used instead of NDVI in calculating the TVDI. In the spatial analysis between the dryness indices and Advanced SCATterometer (ASCAT) surface soil moisture (SSM) using geographically weighted regression (GWR), the results showed the average negative correlation (R) between the variables, while LAI-induced TVDI was more strongly correlated with SSM on average with the $\mathrm{R}$ value improved from -0.59 to -0.62 . Both dryness indices and ASCAT SSM mappings generally showed coherent patterns under low vegetation and dry conditions. Based on these results, the LAI-induced TVDI accuracy as an index for soil moisture status was validated and found appropriate for use as an alternative and complementary method for NDVI-induced TVDI.
\end{abstract}

Key words: Remote Sensing, TVDI, NDVI, LAI, MODIS

Citation: Moon, H. and M. Choi, 2015: Dryness indices based on remotely sensed vegetation and land surface temperature for evaluating the soil moisture status in cropland-forest-dominant watersheds. Terr. Atmos. Ocean. Sci., 26, 599-611, doi: 10.3319/TAO.2015.04.22.01(Hy)

\section{INTRODUCTION}

The ratio of sensible and latent heat fluxes transformed from incoming solar radiation is controlled mainly by the soil moisture status (Dubois et al. 1995; Engman and Chauhan 1995; Patel et al. 2009). Soil moisture measured in a timely and spatially unbiased manner is valuable for a broad range of hydrological applications (Patel et al. 2009). However, the current status of in situ soil moisture observations lacks spatio-temporal continuity and frequency and requires observation technique and protocol standardization (Dorigo et al. 2011). As an alternative to in situ observations, satellite-based remote sensing techniques brought significant changes to water stress detection, with its higher temporal and spatial resolutions (Rahimzadeh-Bajgiran et al. 2012).

\footnotetext{
* Corresponding author

E-mail:mhchoi@skku.edu
}

Aside from the advantages, the retrieved soil moisture from passive microwave sensors has not always shown reasonable congruence with ground measurement observations (Choi et al. 2008; Jackson et al. 2010). Radio frequency interference (RFI) is regarded as one of the critical limitations of conducting observation using microwave sensors. As RFI contamination negatively influences the soil moisture observation in multiple regions, estimating the soil moisture status by interpreting the relationship between land surface temperature $\left(T_{S}\right)$ and vegetation index represents an adequate substitution, since those two products are retrieved and calculated from the visible red band, near infrared band (NIR), and thermal infrared (TIR) band detections (Wan et al. 2004; $\mathrm{Gu}$ et al. 2007). Other passive microwave limitations include its coarse spatial resolution, decreased sensitivity at high vegetation conditions and incapability of detecting deep soil 
moisture (Jackson et al. 1996; Njoku and Entekhabi 1996).

Various researchers have assessed the possibility of evaluating soil moisture status by interpreting the relationship between $T_{S}$ and the Normalized Difference Vegetation Index (NDVI). Moran et al. (1994) introduced the Water Deficit Index (WDI) concept under the assumption that scatter plots of the difference between $T_{S}$ and air temperature $\left(T_{a}\right)$, (i.e., $\mathrm{T}_{\mathrm{S}}-\mathrm{T}_{\mathrm{a}}$ ) and the Soil-Adjusted Vegetation Index (SAVI) exhibit trapezoidal shapes. The WDI was identified applicable to evaluate the evapotranspiration rate and relative field water deficit for the complete fractional vegetation cover range, which solved the problem of Crop Water Stress Index (CWSI) being erroneously affected by soil background in partially vegetated fields (Jackson et al. 1981; Moran et al. 1994). Sandholt et al. (2002) conducted empirical WDI simplification by estimating the $\mathrm{T}_{\mathrm{S}} / \mathrm{NDVI}$ space and suggested the Temperature Vegetation Dryness Index (TVDI) concept. They assumed that the $\mathrm{T}_{S}$ /NDVI space exhibited a triangular shape based on the preceding studies, which concluded the slope of the determined triangle was related to the rate of surface evapotranspiration (e.g., Boegh et al. 1999). The conducted simplification resulted mainly from the decrease in data required to estimate the dryness index. Onsite meteorological data such as the vapor pressure deficit, wind speed, air temperature, and net radiation needed for estimating the WDI, are not needed for estimating the TVDI. The only requirement for TVDI is the satellite data. Such TVDI simplicity led to research addressing the two main shortcomings of the originally developed method: disregard for variations in air temperature within the study area and uncertainty in dense vegetation.

Other research focused on reducing the inaccuracy due to the former cause. Patel et al. (2009) investigated the relation between the TVDI and in situ soil moisture at different depths in Western Uttar Pradesh of India, incorporating a method for calculating TVDI which regarded the minimum edge of $\mathrm{T}_{\mathrm{S}} / \mathrm{NDVI}$ space as a non-constant variable. The TVDI and in situ soil moisture showed negative correlation. Furthermore, the relation between the Antecedent Precipitation Index (API) as an indicator of the surface soil moisture (SSM) was found to have similar temporal variation to the TVDI. Han et al. (2010) applied the same method and analyzed the relationship between the TVDI and five land cover types in the Changbai Mountain area to capture the soil moisture status spatial trend. Several attempts were made to modify the basic TVDI estimation concept. Rahimzadeh-Bajgiran et al. (2012) developed the improved TVDI (iTVDI) which uses $T_{S}-T_{a}$ gradient as the replacement for $T_{S}$ and found it better for detecting soil moisture conditions in mountainous areas where the air temperature variation at altitude is too significant to neglect. Carlà et al. (2012) proposed the multitemporal $\mathrm{T}_{\mathrm{S}}$-Vegetation Index (VI) method, which, by processing the satellite data in a multitemporal sequence, did not demand the data for a single day to cover a full range of soil moisture conditions and fractional vegetation cover.
Many studies pointed out that the early NDVI saturation generates erroneous evapotranspiration and other hydrological variables interpretation and decreases the sensitivity to capture the moisture status of a region with high vegetation conditions, as mentioned above (Sandholt et al. 2002; Patel et al. 2009). Out of this necessity, a modified algorithm concept for estimating the TVDI was introduced by Han et al. (2006), which suggested combining the Leaf Area Index (LAI) and evapotranspiration, with the $\mathrm{T}_{\mathrm{S}}$ /NDVI space. However, that study only suggested conceptual information and actual method application was not conducted. This study applies the NDVI-induced and LAI-induced TVDI method to examine their relationship with the in situ and Advanced SCATterometer (ASCAT) relative SSM. The temporal and spatial variability of dryness indices in the western region of Korea are analyzed. The NDVI, LAI, and $\mathrm{T}_{\mathrm{S}}$ data used in this study were derived from Moderate Resolution Imaging Spectroradiometry (MODIS), from March 29 to November 08, in 2012.

\section{STUDY AREA AND DATA}

\subsection{The Western Basins of Korea}

South Korea lies in the middle-latitude temperate climatic zone, located in Northeast Asia. The annual mean air temperature ranges from $10-15^{\circ} \mathrm{C}$ across the peninsula. The annual rainfall in South Korea varies from 900 - 1300 mm.

The $33201 \mathrm{~km}^{2}$ study area lies in the western part of South Korea, covering latitude $34.14-37.16^{\circ} \mathrm{N}$ and longitude $125.01-128.00^{\circ} \mathrm{E}$, consisting of 10 sub-basins, where the dominant soil types are loam and sandy loam (Fig. 1). The study area was selected for this research because of its relatively broad range of NDVI and LAI values, and so that the full range of fractional vegetation can be covered. The area consists of flatland and low mountainous regions (mostly $100-400 \mathrm{~m}$ ) where the altitude variation effect on temperature is not crucial. The main land cover types are cropland $(42.80 \%)$, followed by mixed forest $(30.07 \%)$, deciduous broadleaf forest $(10.68 \%)$, woody savannas (7.80\%), and others. The elevation and land cover spatial distribution types are also shown in Figs. $1 \mathrm{~b}$ and c. The study area vegetation characteristic is appropriate for examining the suggested method empirical validity. Forests are distributed mostly in mountainous areas with elevation higher than $200 \mathrm{~m}$, corresponding to the typical distribution of vegetation in South Korea described in Kang et al. (2003). Detailed descriptions of the seven in situ measurement sites are given in Table 1. The site selection was conducted based on data availability and quality.

\subsection{Description of Dataset}

The MODIS products used in this study are of $1 \mathrm{~km}$ resolution including MOD09A1 8-day Surface reflectance 
for calculating NDVI, MOD15A2 LAI, and MOD11A1 $\mathrm{T}_{\mathrm{S}}$ from satellite Terra. The MODIS is mounted on the National Aeronautics and Space Administration (NASA) Earth Observation System (EOS) satellites Terra and Aqua, which were launched separately in December 1999 and May 2002.
MODIS observes the Earth's biophysical properties and atmosphere, land and ocean processes, with 36 spectral bands, of which the spatial resolutions range from $250 \mathrm{~m}$ to $1 \mathrm{~km}$. The temporal resolution is more than twice a day (Masuoka et al. 1998; Salomonson et al. 2002; Hwang and Choi 2013).

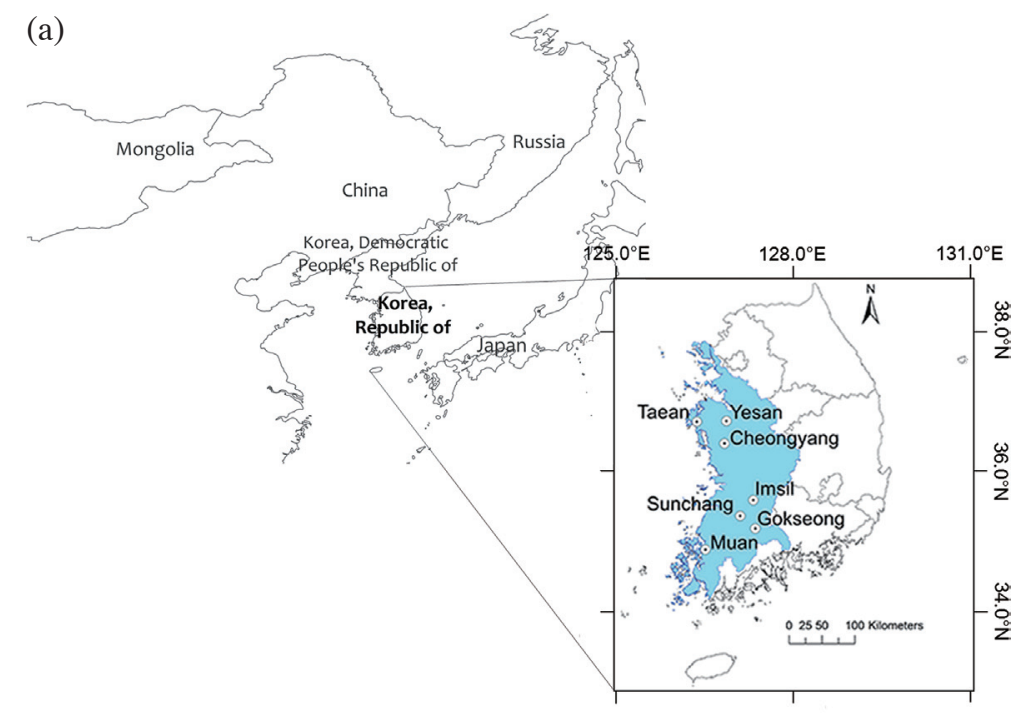

(b)

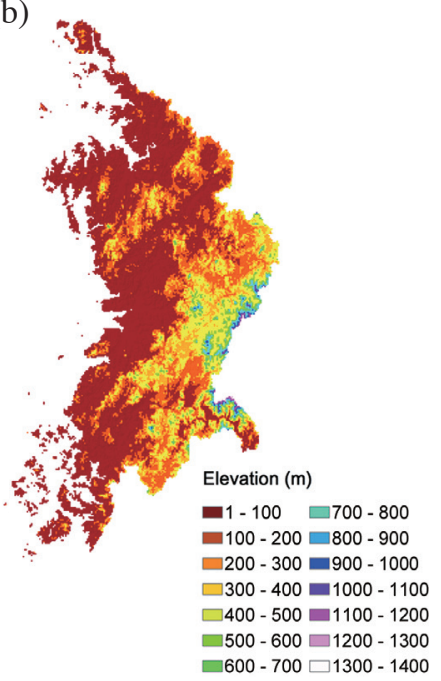

(c)

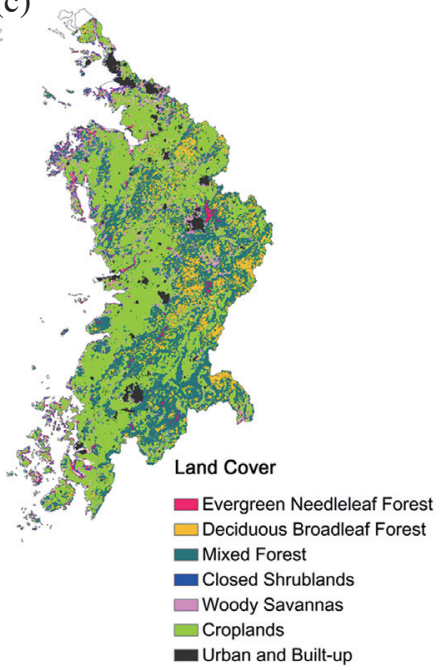

Fig. 1. (a) The location of seven in situ sites, (b) Digital Elevation Model (DEM) and (c) Land Cover Map of the study area.

Table 1. Descriptions of the in situ soil moisture measurement sites.

\begin{tabular}{ccccc}
\hline Site & Latitude $\left(^{\circ}\right)$ & Longitude $\left(^{\circ}\right)$ & Soil Texture & Land Cover \\
\hline Sunchang & 35.44 & 127.04 & Loam & Deciduous broadleaf forest \\
Taean & 36.73 & 126.31 & Loam & Croplands \\
Yesan & 36.74 & 126.81 & Loam & Croplands \\
Cheongyang & 36.43 & 126.78 & Loam & Mixed forests \\
Muan & 34.98 & 126.47 & Loam & Croplands \\
Imsil & 35.65 & 127.27 & Silt loam & Croplands \\
Gokseong & 35.27 & 127.30 & Loam & Croplands \\
\hline
\end{tabular}


The satellite Terra overpass time is 10:30 AM (descending) and 10:30 PM (ascending); while that of satellite Aqua is 01:30 AM (descending), and 01:30 PM (ascending).

The $T_{S}$ is retrieved from brightness temperatures with the generalized split-window algorithm (Wan and Dozier 1996; Wan et al. 2004). Cloudy pixels are deleted from the $T_{S}$ retrieving process, since TIR signals do not penetrate clouds, deriving confusion with cloud-top temperature (Wan et al. 2004). The MOD11A1 $T_{S}$ is generated on a daily basis with a spatial resolution of $1 \mathrm{~km}$. We calculated 8-day mean $\mathrm{T}_{\mathrm{S}}$ to match the temporal resolution along with other parameters.

The NDVI was calculated as a normalized ratio of NIR and red bands from 8-day surface reflectance product which successfully reflects the chlorophyll and mesophyll in the vegetation canopy (Chen and Brutsaert 1998; Heute et al. 2002; Gu et al. 2007). The $500 \mathrm{~m}$ surface reflectance pixels of MOD09A1 were aggregated into $1 \mathrm{~km}$ to match the spatial resolution with $\mathrm{LAI}$ and $\mathrm{T}_{\mathrm{S}}$.

The LAI definition is, in broadleaf canopies, the ratio of one-sided green leaf area to unit ground area; and in coniferous canopies, the ratio of hemi surface needle leaf area to unit ground area (Chen and Black 1992; Wang et al. 2004). The MODIS LAI products are retrieved from the Look-up Table (LUT), which stores numerical solutions for the three-dimensional radiative transfer equation for estimating the biome-specific surface reflectance of a wide range of vegetation canopies and soil patterns (Knyazikhin et al. 1998; Fensholt et al. 2004; Wang et al. 2004). The MOD15A2 LAI/Fraction of Photosynthetically Active Radiation (FPAR) product is composited every 8 days with the spatial resolution of $1 \mathrm{~km}$.

The ASCAT SSM was used in this study as a source of dryness indices spatial comparison. ASCAT is a real-aperture radar sensor, which succeeded the ERS-1/2 scatterometer, measuring C-band radar backscatter at global scale on a daily time step (Brocca et al. 2010; Verspeek et al. 2010). The ASCAT SSM does not directly refer to the volumetric soil moisture; but it is a suitable index that represents SSM as saturation degree, with a high coefficient of correlation with in situ SSM (Albergel et al. 2009; Brocca et al. 2010). The ASCAT SSM accuracy in South Korea was evaluated by Cho et al. (2015) in comparison with in situ soil moisture and Advanced Microwave Scanning Radiometer-EOS (AMSR-E) SSM. It was found that ASCAT SSM on average showed better correlation coefficient and root mean square error (RMSE) than AMSR-E based SSM retrieval products in nine point scale soil moisture measurement sites. In this study, $12.5 \mathrm{~km}$-resolution maps of the ASCAT SSM product were used without conversion into volumetric soil moisture.

The in situ soil moisture measurements used in analysis with the TVDI are 8-day mean of hourly measured soil moisture. Hourly soil moisture observations were conducted at single point networks administered by Rural Development Administration (RDA) (Table 1). The measurements conducted by RDA were installed with the Time Domain Reflectometry sensors only at the near-surface.

\section{METHODS}

\subsection{NDVI-Induced TVDI}

Under the theoretical basis that a scatterplot of satellite-based remote sensing $T_{S}$ and NDVI data exhibits a triangular shape (Price 1990), with the full range of fractional vegetation cover and soil moisture status, the TVDI concept was defined as the estimation of the proportion between lines A and B in Fig. 2 (Sandholt et al. 2002). Each point in the scatterplot is denoted as $\mathrm{T}_{\mathrm{S}}$ and NDVI from each pixel. All values from pixels covering the study area are plotted as triangular shapes. Line A denotes the difference between the minimum surface temperature and line $\mathrm{B}$ denotes the maximum difference between surface temperature values. The formulaic expression of TVDI is:

TVDI $=\frac{T_{S}-T_{S_{\text {min }}}}{T_{S_{\text {max }}}-T_{S_{\text {min }}}}$

where $T_{S}$ is the surface temperature of the given pixel, $T_{S \text { min }}$ is the minimum surface temperature of the $\mathrm{T}_{\mathrm{S}} / \mathrm{NDVI}$ space, and $\mathrm{T}_{\mathrm{S} \text { max }}$ is the maximum surface temperature of the NDVI value equal to the NDVI of the given pixel. The calculation of $T_{S \max }$ is derived from the linear regression of the slope of $\mathrm{T}_{\mathrm{S}}$ /NDVI space, which is simply expressed as

$\mathrm{T}_{\mathrm{S} \max }=a \times \mathrm{NDVI}+b$

where, $b$ is the intercept of dry edge which is the hypotenuse of a right-angled triangle in Fig. 2, and $a$ is the slope of the dry edge. The TVDI value of the pixels located on the dry edge is 1 , the maximum value of the TVDI, which means the driest condition. The lower the TVDI, the wetter the condition; and the minimum value is 0 .

The $T_{\mathrm{S}} / \mathrm{NDVI}$ spaces were obtained for 23 dates during March 29 to November 08 in 2012, of which the percentages of cloudless pixels for both the NDVI and LAI in the proposed study area were more than $85 \%$. The NDVI and LAI were mutually masked to obtain the areas where both variables were available to calculate dryness indices. The minimum percentage of $85 \%$ was set to ensure that the derived $\mathrm{T}_{\mathrm{S}} / \mathrm{NDVI}$ space ranges from bare soil to fully vegetated soil and from dry status to saturated status.

\subsection{LAI-Induced TVDI}

The NDVI has been a key variable as a useful indicator of vegetation conditions on land in numerous studies conducted since the advent of satellite remote sensing, despite its several limitations (Carlson and Ripley 1997). The 
convergence of the NDVI value in its correlation with the LAI is one of the major limitations to consider (Carlson and Ripley 1997). In comparison with the LAI the NDVI begins to present an asymptotic regime where the value of the LAI is $3-4$, which varies, depending on the crop type. This type of relationship between the two variables was found to fit an exponential equation (Hatfield et al. 1984; Baret and Guyot 1991), as shown in Eq. (3).

$\mathrm{VI}=\mathrm{VI}_{\infty} \times\left(\mathrm{VI}_{\mathrm{g}}-\mathrm{VI}_{\infty}\right) \times \exp \left(-\mathrm{K}_{\mathrm{VI}} \times \mathrm{LAI}\right)$

where, $\mathrm{VI}_{\infty}$ is the asymptotic value of VI when LAI tends towards infinity, $\mathrm{VI}_{\mathrm{g}}$ is the vegetation index corresponding to that of the bare soil, and $\mathrm{K}_{\mathrm{VI}}$ is a coefficient that controls the slope of the relationship. The insensitivity of the NDVI in highly vegetated regions denotes potential TVDI error in its application for capturing the soil moisture status. Sandholt et al. (2002) indicated that the influence of uncertainties in estimating TVDI parameters was maximized at higher NDVI values. Therefore, in this study, the LAI-induced TVDI calculation approach is adopted. Based on the relationship between the NDVI and LAI , which is simply expressed by Eq. (3), the nonlinear regression line equation for the dry edge in $\mathrm{T}_{\mathrm{S}} / \mathrm{LAI}$ space can be fitted as the following equation,

$\mathrm{T}_{\mathrm{S} \max }=\alpha \times \exp (-\beta \times \mathrm{LAI})+\gamma$

where, $\alpha, \beta$, and $\gamma$ are empirical constants that are determined based on the $T_{S} / L A I$ space, using the steepest descent method in Matlab. After the determination of $\mathrm{T}_{\mathrm{S} \text { max }}$, the LAI-induced TVDI is calculated as Eq. (1).

\subsection{Geographically Weighted Regression}

The geographically weighted regression (GWR) analysis was conducted in this study for a quantitative analysis between two variables along with the qualitative visual comparison between the dryness indices and ASCAT SSM mappings. Comparing to the basic linear regression model, GWR assumes the spatial non-stationarity of the relationship among variables which means that the relationship may be a function of location (Fotheringham et al. 2002; Foody 2003). In the regression model, a weighting matrix is considered to make observations near the location at which parameters were estimated have a larger influence on the analysis than those further away (Foody 2003). A conventional Gaussian GWR model, which was adopted in this study, can be described as

$y_{i}=\sum_{k} \mu_{k}\left(u_{i}, v_{i}\right) x_{k, i}+\varepsilon_{i}$

where $y_{i}$ is the dependent variable, $x_{k, i}$ is the $k$ th indepen- dent variable, $\varepsilon_{i}$ is the Gaussian error, $\left(u_{i}, v_{i}\right)$ is the $x$ and $y$ coordinate of the $i$ th location and $\mu_{k}\left(u_{i}, v_{i}\right)$ is the coefficient varying on the location. Equation (5) can be developed and applied in this study as

$\mathrm{SSM}_{i}=\mu_{0}\left(\mathrm{X}_{i}, \mathrm{Y}_{i}\right)+\mu_{1}\left(\mathrm{X}_{i}, \mathrm{Y}_{i}\right) \mathrm{TVDI}_{i}$

where $\mathrm{SSM}_{i}$ is ASCAT SSM, TVDI ${ }_{i}$ can either be NDVI- or LAI-induced TVDI and $\mu_{0}\left(\mathrm{X}_{i}, \mathrm{Y}_{i}\right)$ is the coefficient representing the intercept in the regression model and $\mu_{1}\left(\mathrm{X}_{i}, \mathrm{Y}_{i}\right)$ is the coefficient representing the slope in the regression model in a location $\left(\mathrm{X}_{i}, \mathrm{Y}_{i}\right)$. A more detailed GWR theoretical description can be found in Brunsdon et al. (1996) and Fotheringham et al. (2002).

\section{RESULTS AND DISCUSSION}

\section{1 $\mathrm{T}_{\mathrm{S}} / \mathrm{NDVI}$ and $\mathrm{T}_{\mathrm{S}} / \mathrm{LAI}$ Spaces}

Figures 3 and 4 show the figurative characteristics of each scatterplot which are distinguishable, in terms of overall shapes, and dry edge features. The $\mathrm{T}_{\mathrm{S}} / \mathrm{NDVI}$ spaces over the period before the rainy season (DOY 182) exhibited definite triangular shapes with large variations in both the NDVI and $\mathrm{T}_{\mathrm{S}}$ values, which were sufficient for TVDI parameter determination (Fig. 3). The dry edges were linearly regressed using the maximum value for $\mathrm{T}_{\mathrm{S}}$ at each 0.01 NDVI interval. The $T_{S} / N D V I$ spaces affected by the rainfall events resulted in smaller variation in $\mathrm{T}_{\mathrm{S}}$ values and gentler dry edge slopes. After the beginning of the rainy season the plots tended to concentrate in higher NDVI values, which led to unclearly defined $\mathrm{T}_{\mathrm{S}} / \mathrm{NDVI}$ spaces.

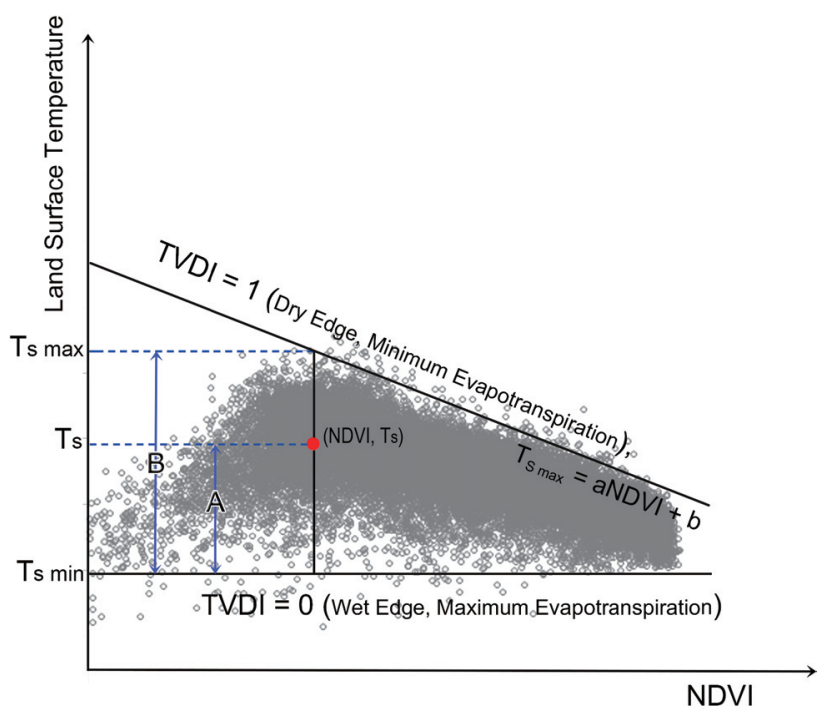

Fig. 2. The definition of the Temperature Vegetation Dryness Index (TVDI). TVDI for a given pixel (Normalized Difference Vegetation Index: NDVI, Land surface temperature: $\mathrm{T}_{\mathrm{S}}$ ) is estimated as the proportion between lines A and B. 

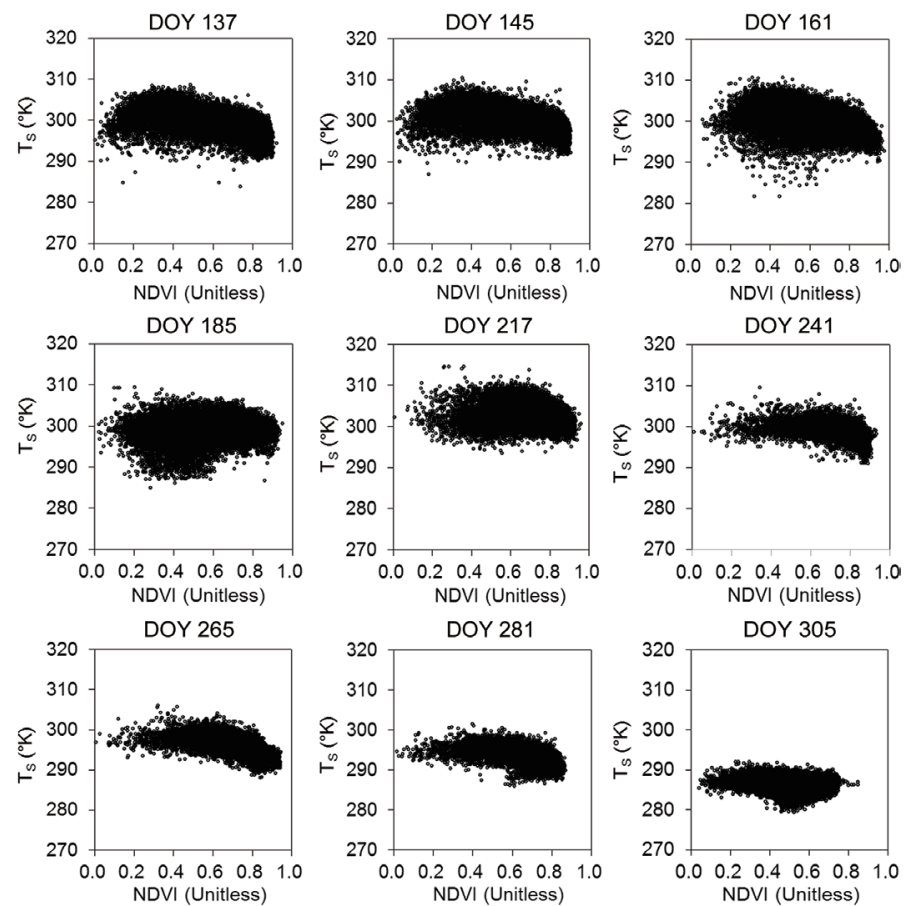

Fig. 3. Scatterplots of NDVI and $\mathrm{T}_{\mathrm{S}}$ (nine images out of twenty three images used in this study).
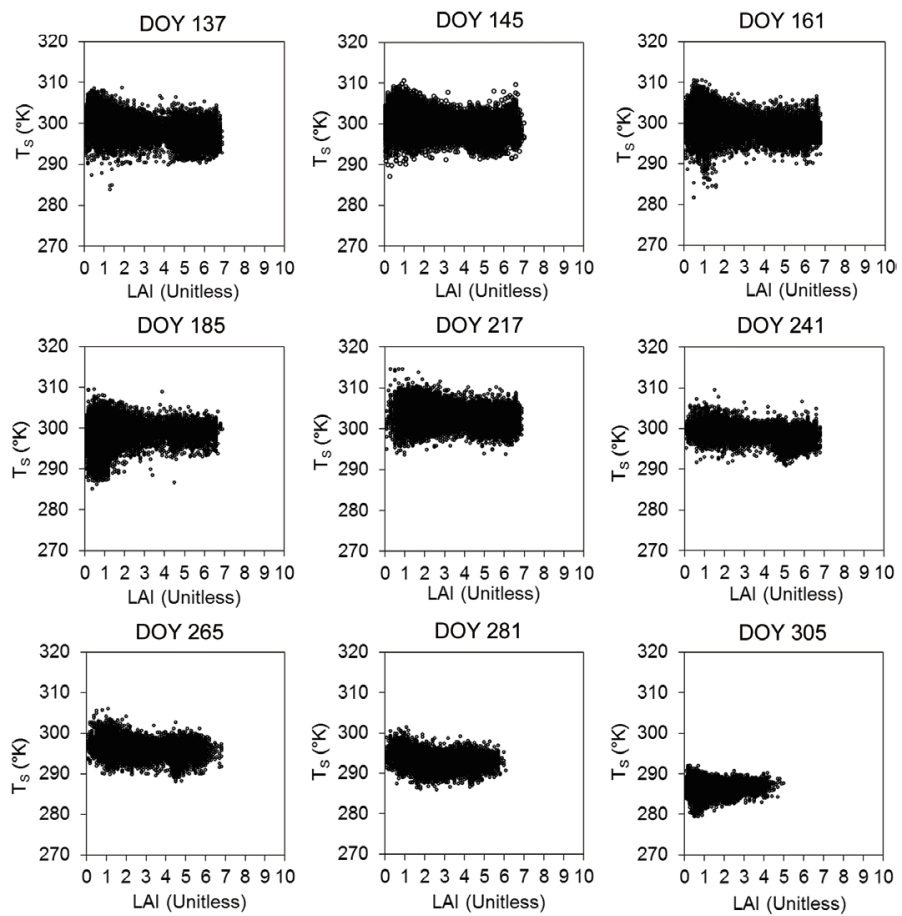

Fig. 4. Scatterplots of Leaf Area Index (LAI) and $\mathrm{T}_{\mathrm{S}}$ (nine images out of twenty three images used in this study).

Curves are formed in the dry edges where NDVI values higher than 0.8 are present on every scatterplot. Mallick et al. (2009) found a similar trend in the $T_{S} / \mathrm{NDVI}$ spaces derived from Advanced Space-borne Thermal Emission and reflection Radiometer (ASTER), and attributed it to attenuation of upwelling longwave radiation coming from the soil. Furthermore, the fine resolution $(90 \mathrm{~m})$ of ASTER data, which they found was minute enough not to smooth out the asymptotically increasing NDVI phase. In this study data with coarser resolution $(1 \mathrm{~km})$ also exhibited a similar 
pattern. This was caused from the differences in land cover type distribution, which was mostly cropland in the study of Mallick et al. (2009) and the equivalent mix of croplands and forests in this study.

The dry edge slopes of $\mathrm{T}_{S} / \mathrm{LAI}$ spaces formed exponentially decaying curves, of which the parameters were found by applying the steepest descent method in Matlab, with initial values empirically determined from the dataset (Fig. 4). Figure 5 shows an example of dry edge nonlinear regression at DOY 153 and the maximum $T_{S}$ values for each 0.1 interval of LAI are only presented. The variation in LAI values is fairly maintained at around 7 , regardless of rainfall events, with a minimum value of 0 and a maximum value of 7 . Dry edge intercepts of the $T_{S} / L A I$ space were the same or slightly lower over the whole period, since the scatterplots are more adjacent to the $y$-axis of $T_{S}$, than in the $\mathrm{T}_{S} / \mathrm{NDVI}$ space. Considering the analysis results from two different scatterplots, it can be presented that the $T_{S} / L A I$ spaces are more resistant to seasonal changes in vegetation, which makes the dryness index calculation procedure based on them less assumptive.

The group of points from low vegetation index value $(\mathrm{NDVI}<0.3$ and $\mathrm{LAI}<0.5)$ with low $\mathrm{T}_{\mathrm{S}}$ values located relatively far from the fitted dry edge lines were both found in the $\mathrm{T}_{\mathrm{S}} / \mathrm{NDVI}$ and $\mathrm{T}_{\mathrm{S}} / \mathrm{LAI}$ spaces. We inspected the areas where those points were derived (not shown here) and most of them were found to be located in coastal regions. Thus, it should be considered that the group of points produced from coastal region geophysical characteristics and may also be erroneously affected (Hill et al. 2006).

As shown in Fig. 6, the dry and wet edge intercepts tend to follow a similar temporal variation, while keeping the difference between their values in the $14-35^{\circ} \mathrm{K}$ range. A similar variation brought considerably high correlation coefficients found in relationships between minimum $T_{S}$ and each dry intercept ( $\mathrm{T}_{\mathrm{S}} / \mathrm{NDVI}$ : $0.72, \mathrm{~T}_{\mathrm{S}} / \mathrm{LAI}$ : 0.70$)$. The slopes and the coefficient of exponent $(\beta)$ that determined the dry edge decaying pattern in each scatterplot apparently had no specific temporal trends (Fig. 7). The variations in the two parameters were not totally coinciding, however, in both cases, the largest variation was found in the drier period when rainfall events were less frequent. This randomly varying temporal evolution of these parameters, which indicated the effect of complex interaction of highly variable forcings on them, was also reported in other studies (Goetz 1997; Sandholt et al. 2002).

\subsection{Relationship Between the NDVI- and LAI-Induced TVDI, and the Soil Moisture and Precipitation}

Table 2 shows the correlation coefficient and P-value from the linear correlation between the parameters at each site. The negative correlation between the top soil moisture and dryness indices calculated from the vegetation index/
$\mathrm{T}_{\mathrm{S}}$ spaces were recurrently examined, and found by several earlier studies (Sandholt et al. 2002; Han et al. 2010; Rahimzadeh-Bajgiran et al.2012). At all sites soil moisture was

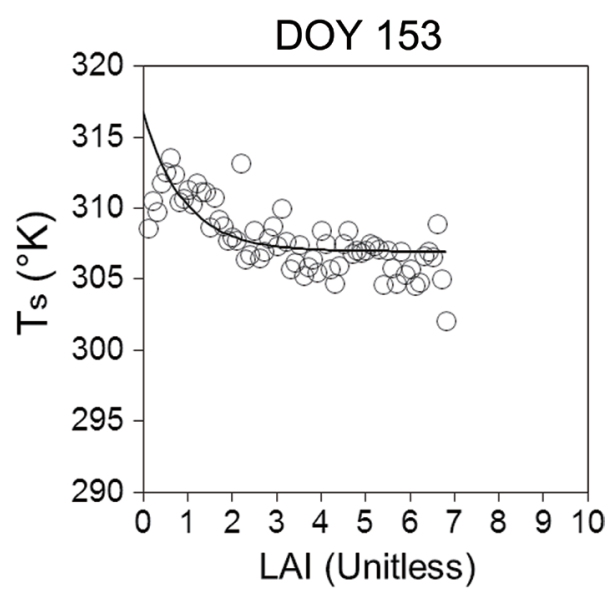

Fig. 5. An example of nonlinear regression for $\mathrm{LAI} / \mathrm{T}_{\mathrm{S}}$ space dry edge (DOY 153).

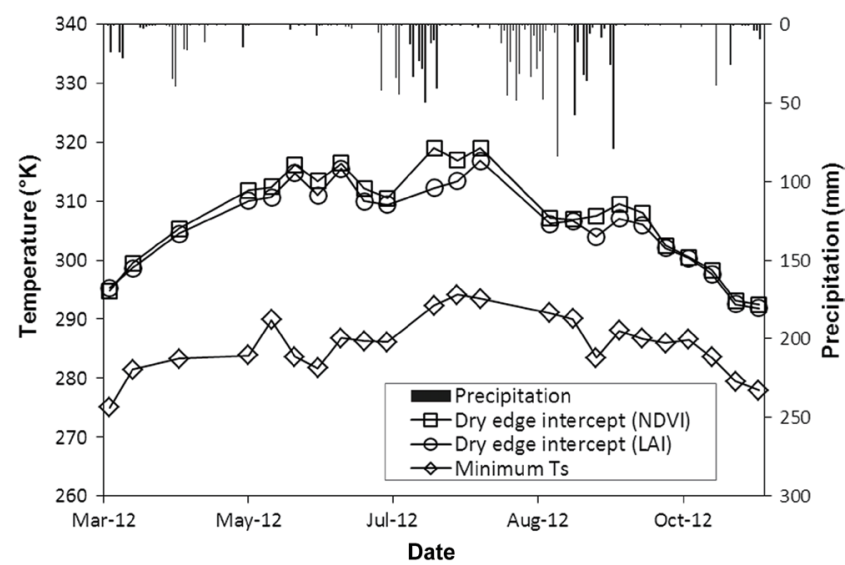

Fig. 6. Temporal variability in dry edge intercepts, minimum $\mathrm{T}_{\mathrm{S}}$ and precipitation.

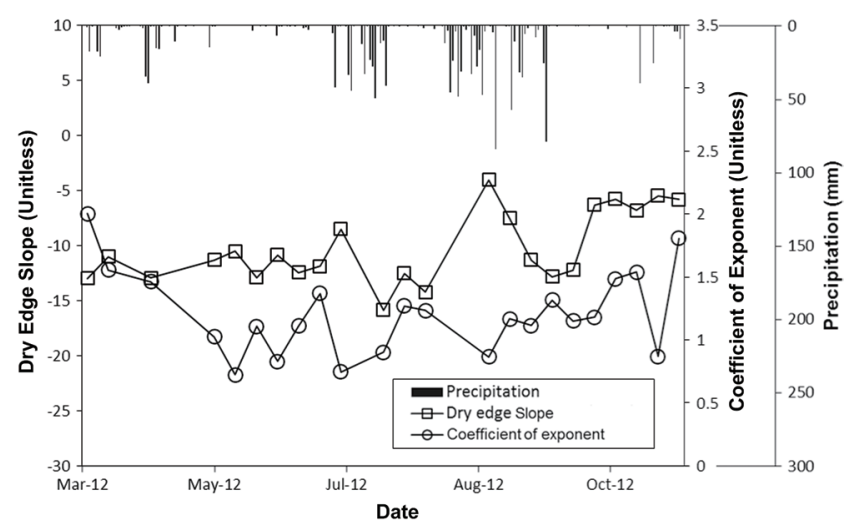

Fig. 7. Temporal variability in dry edge slopes, coefficient of exponents $(\beta)$ and precipitation. 
Table 2. Linear correlation between NDVI-induced TVDI, LAI-induced TVDI, and in situ soil moisture and precipitation at 7 sites.

\begin{tabular}{|c|c|c|c|c|c|}
\hline \multirow{2}{*}{ Sites } & \multirow{2}{*}{ Parameters } & \multicolumn{2}{|c|}{ NDVI-induced TVDI } & \multicolumn{2}{|c|}{ LAI-induced TVDI } \\
\hline & & $\mathbf{R}$ & P-value & $\mathbf{R}$ & P-value \\
\hline \multirow{2}{*}{ Sunchang } & $0-10 \mathrm{~cm}$ soil moisture & -0.119 & 0.587 & -0.025 & 0.909 \\
\hline & 8-day precipitation & $-0.373 *$ & 0.031 & -0.266 & 0.080 \\
\hline \multirow{2}{*}{ Taean } & $0-10 \mathrm{~cm}$ soil moisture & -0.085 & 0.701 & $-0.457 *$ & 0.049 \\
\hline & 8-day precipitation & -0.027 & 0.216 & -0.161 & 0.197 \\
\hline \multirow{2}{*}{ Yesan } & $0-10 \mathrm{~cm}$ soil moisture & -0.254 & 0.242 & -0.355 & 0.101 \\
\hline & 8 -day precipitation & 0.007 & 0.481 & -0.102 & 0.362 \\
\hline \multirow{2}{*}{ Cheongyang } & $0-10 \mathrm{~cm}$ soil moisture & $-0.469^{*}$ & 0.024 & $-0.457 *$ & 0.037 \\
\hline & 8-day precipitation & -0.238 & 0.103 & $-0.286^{*}$ & 0.042 \\
\hline \multirow{2}{*}{ Muan } & $0-10 \mathrm{~cm}$ soil moisture & -0.156 & 0.489 & -0.241 & 0.570 \\
\hline & 8 -day precipitation & -0.124 & 0.372 & -0.108 & 0.093 \\
\hline \multirow{2}{*}{ Imsil } & 0 - $10 \mathrm{~cm}$ soil moisture & -0.204 & 0.361 & $-0.427 *$ & 0.048 \\
\hline & 8 -day precipitation & $-0.592 *$ & 0.022 & $-0.653 *$ & 0.021 \\
\hline \multirow{2}{*}{ Gokseong } & $0-10 \mathrm{~cm}$ soil moisture & -0.325 & 0.150 & -0.443 & 0.077 \\
\hline & 8 -day precipitation & $-0.582 *$ & 0.035 & $-0.621 *$ & 0.021 \\
\hline \multicolumn{2}{|r|}{ Average } & -0.253 & & -0.329 & \\
\hline
\end{tabular}

Note: *: Correlation is significant at 0.05 level.

found to be negatively correlated with the NDVI- and LAIinduced TVDI while the average correlation coefficient (R) was improved from -0.253 to -0.329 when using LAI. The best significant relationship was found at the Cheongyang site (R: -0.469/-0.457, P-value: 0.024/0.037). The different correlations between in situ soil moisture and the dryness indices at each site may be affected by the surrounding geological and vegetative conditions. The correlation between the dryness indices and near-SSM was relatively significant compared to the previous satellite soil moisture product validation study conducted in South Korea (Choi and Hur 2012). The within-pixel spatial heterogeneity in Sunchang has been visually inspected using Google Earth (not shown here), which has finer spatial resolution than the MODIS Land Cover Type product. As the remote sensing measurements provide predominant or averaged footprint condition, the observation accuracy in those sites could be presumably influenced by the spatial heterogeneity (Loew 2008; Shin and Mohanty 2013). The 8-day-mean precipitation at each site was used for comparison with the NDVI- and LAIinduced TVDI in the same temporal resolution. The correlation between the dryness indices and precipitation were slightly different from the correlation with moisture at each site. While the strongest correlation between the dryness indices and soil moisture was found in Cheongyang, the strongest precipitation and dryness indices correlation was found in Imsil where the former was quite moderate.

\subsection{Spatial Variation in the NDVI- and LAI-Induced TVDI, Compared with the ASCAT SSM}

The comparative analysis using GWR was conducted to evaluate the dryness indices and ASCAT SSM spatial distributions. The GWR models were built for each 8-day dryness indices and SSM and we have checked the non-stationarity between the variables of which relationship can be better described by the relationship varying with the location rather than constant. Table 3 shows the GWR results with the correlation coefficient, slope and intercept spatial averages on each day. The averagely negative value of the slope coefficient shows that the ASCAT SSM and both dryness indices were negatively correlated as expected. The LAIinduced TVDI was found to be somewhat better correlated with the ASCAT SSM (Table 3). On DOY 113 both dryness indices were found to be positively correlated according to the slope coefficients resulting from GWR (10.01 and 11.77). These abnormal correlations between the variables are also visible in Fig. 8a, where the dryness indices and SSM spatial distributions are apparently contrasting. The precipitation that occurred on corresponding dates erroneously affected the dryness indices accuracy as well as the $\mathrm{T}_{\mathrm{S}} / \mathrm{VI}$ spaces in the former chapter.

Figure 8 shows the NDVI- and LAI-induced TVDI maps in $1 \mathrm{~km}$-resolution and ASCAT SSM maps in $12.5 \mathrm{~km}$-resolution, over the study area, on dates in the spring, summer, 
and fall season, with various soil conditions. Through whole seasons croplands were found to be drier than the forest areas, in NDVI-, LAI-induced TVDI, and ASCAT SSM mappings. This result matched the study of Han et al. (2010), which also found that forest areas had better moisture conditions than cropland areas, in the Great Changbai Mountains, China. The spatial distributions visually matched better during the period with no or little precipitation in all seasons, under the assumption that the relationship between the variables remains constant. The clearest spatial correlation between the variables can be found in the DOY 289 mappings where vegetation condition was relatively low and little precipitation was observed. During the peak growing season (Figs. 8c and d), weak correlations between indices and soil moisture was found which might be derived from the $\mathrm{T}_{\mathrm{S}} / \mathrm{VI}$ spaces. This was also reported in a previous study (Mallick et al. 2009). These patterns resulted from multilayer leaves in the forest, which caused increased attenuation.

\section{CONCLUSIONS}

The LAI-induced TVDI was applied with NDVI-induced TVDI in this study to evaluate and compare their ability to estimate soil wetness in South Korea. The study area was selected to examine the performance of the proposed method. Figurative and temporal $\mathrm{T}_{\mathrm{S}} / \mathrm{NDVI}$ and $\mathrm{T}_{\mathrm{S}} / \mathrm{LAI}$ scatterplot analyses were conducted. The dryness indices calculated from each scatterplot were compared with in situ soil moisture and ASCAT SSM.

The $\mathrm{T}_{\mathrm{S}} / \mathrm{LAI}$ space presented different aspects from the $T_{S} /$ NDVI space, specifically in its dry edge, which was found to be well fitted to the exponentially decaying form. The TVDI derived from the $\mathrm{T}_{\mathrm{S}} / \mathrm{LAI}$ space with the proposed method was examined to be well correlated with the moisture condition of the area, as well as the result from the method using the $\mathrm{T}_{\mathrm{s}} / \mathrm{NDVI}$. This finding is meaningful, since there have not been studies available that demonstrated incorporating

Table 3. Results of geographically weighted regression (GWR) between dryness indices and ASCAT SSM.

\begin{tabular}{c|ccc|ccc}
\hline \multirow{2}{*}{ DOY } & \multicolumn{2}{|c|}{ NDVI-induced TVDI } & \multicolumn{3}{c}{ LAI-induced TVDI } \\
\cline { 2 - 7 } & $\mathbf{R}$ & slope & intercept & R & slope & intercept \\
\hline 89 & -0.74 & -17.13 & 70.86 & -0.73 & -3.19 & 60.87 \\
97 & 0.68 & 0.90 & 54.39 & 0.75 & 4.62 & 51.81 \\
113 & 0.67 & 10.01 & 59.37 & 0.67 & 11.77 & 57.83 \\
137 & -0.81 & -39.04 & 66.31 & -0.87 & -41.81 & 68.95 \\
145 & -0.83 & -43.84 & 62.26 & -0.89 & -48.93 & 65.56 \\
153 & -0.87 & -99.58 & 105.28 & -0.88 & -103.51 & 108.56 \\
161 & -0.87 & -91.71 & 102.01 & -0.87 & -95.77 & 106.24 \\
169 & -0.87 & -92.06 & 95.71 & -0.90 & -100.74 & 101.63 \\
177 & -0.84 & -30.80 & 63.01 & -0.85 & -37.51 & 68.69 \\
185 & -0.84 & -35.63 & 86.13 & -0.83 & -39.91 & 89.15 \\
201 & -0.83 & -39.44 & 75.72 & -0.87 & -40.98 & 79.15 \\
209 & -0.80 & -52.90 & 72.30 & -0.86 & -48.19 & 71.10 \\
217 & -0.78 & -61.59 & 87.33 & -0.91 & -61.69 & 88.02 \\
241 & -0.73 & -31.73 & 84.09 & -0.72 & -29.75 & 85.53 \\
249 & -0.74 & -22.25 & 73.64 & -0.76 & -21.37 & 73.98 \\
257 & -0.75 & -15.64 & 79.86 & -0.88 & -19.53 & 83.26 \\
265 & -0.71 & -36.20 & 74.86 & -0.74 & -29.76 & 70.94 \\
273 & -0.75 & -17.36 & 57.01 & -0.74 & -12.93 & 54.23 \\
281 & -0.73 & -21.94 & 54.74 & -0.72 & -21.77 & 55.41 \\
289 & -0.79 & -17.08 & 50.89 & -0.83 & -15.89 & 50.57 \\
297 & -0.72 & -8.37 & 60.36 & -0.77 & -6.90 & 59.60 \\
305 & -0.71 & -12.90 & 61.28 & -0.77 & -12.94 & 61.00 \\
313 & 0.68 & 7.22 & 55.91 & 0.68 & 6.31 & 56.33 \\
\hline Average & $\mathbf{- 0 . 5 9}$ & $\mathbf{- 3 3 . 4 4}$ & $\mathbf{7 1 . 8 8}$ & $\mathbf{- 0 . 6 2}$ & $\mathbf{- 3 3 . 4 9}$ & $\mathbf{7 2 . 5 4}$ \\
\hline & & & & & & \\
\hline
\end{tabular}


(a)
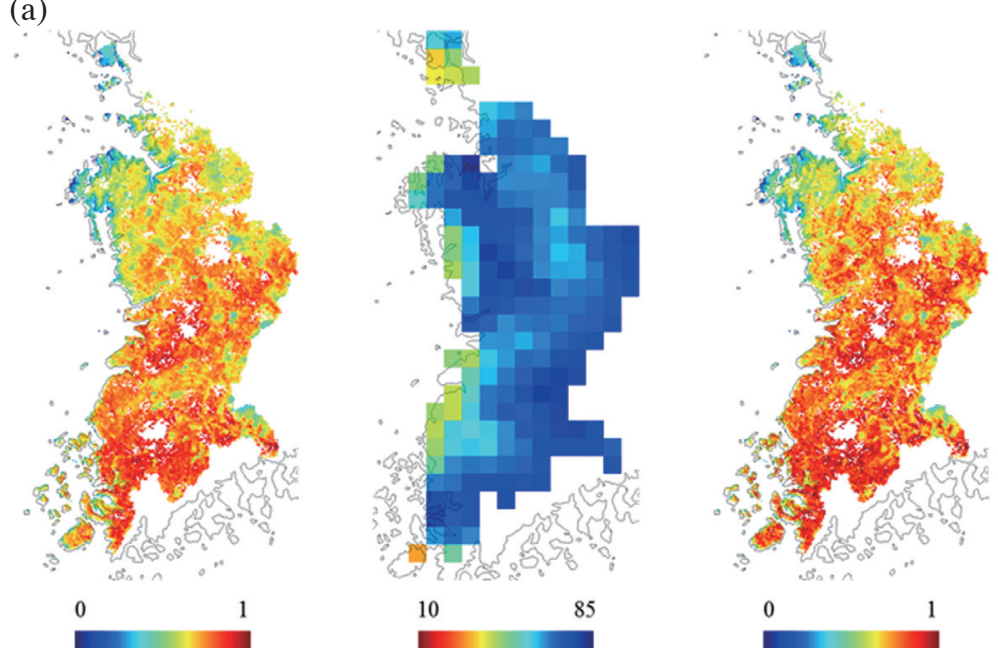

VI-induced TVDI (Unitless)

10

85

0

ASCAT SSM (\%)

AI-induced TVDI (Unitless)

On DOY113 (22 April, Spring, Wet)

(b)
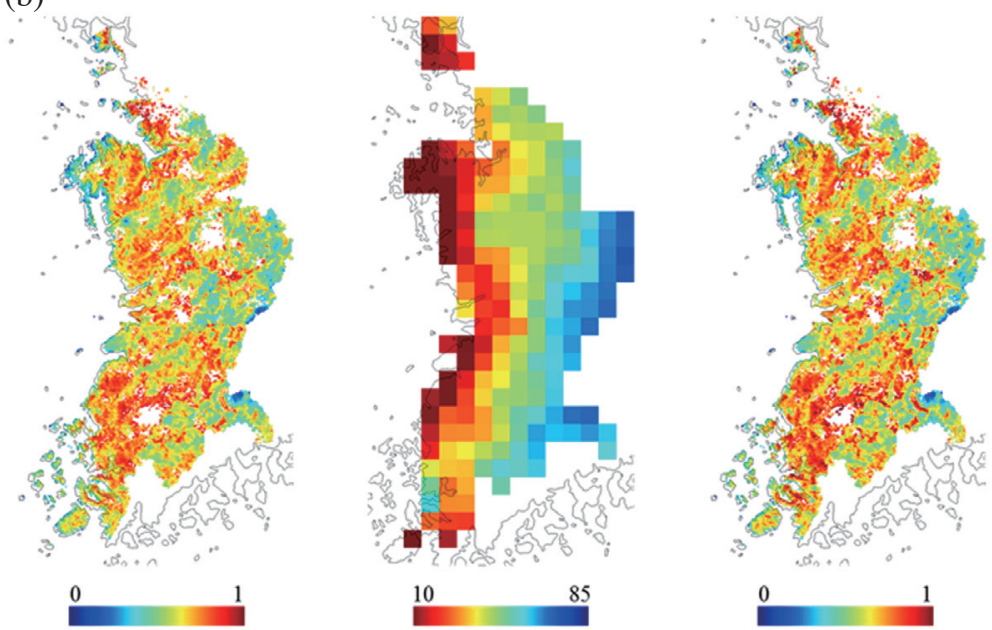

NDVI-induced TVDI (Unitless)

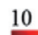

0

LAI-induced TVDI (Unitless)

ASCAT SSM (\%)

On DOY145 (24 May, Spring, Dry)

(c)
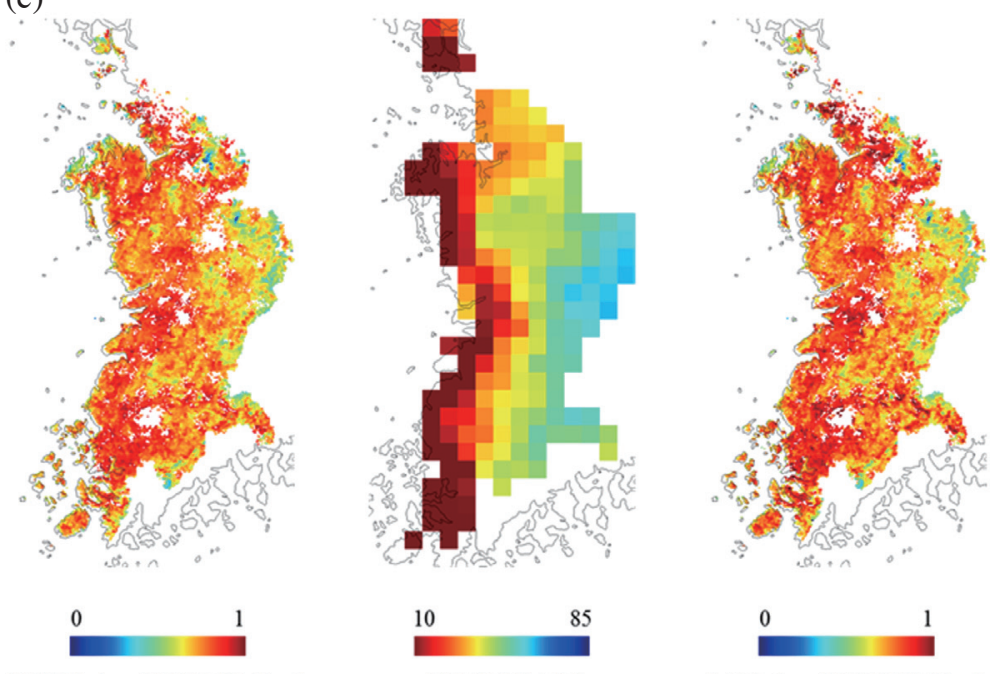

NDVI-induced TVDI (Unitless)

ASCAT SSM (\%)

LAI-induced TVDI (Unitless)

On DOY161 (09 June, Summer, Dry)

Fig. 8. Spatial variations in NDVI-induced TVDI, Advanced SCATterometer surface soil moisture (ASCAT SSM), and LAI-induced TVDI. 
the LAI with the TVDI method (Han et al. 2006).

Temporal and spatial analyses of each dryness index were also examined and compared with soil moisture and precipitation. The temporal variation of the deterministic parameters for both dryness indices showed no apparent patterns, which matched with previous studies, while the parameters and the characteristics of $\mathrm{T}_{\mathrm{S}} / \mathrm{VI}$ spaces were affected strongly by rainfall events. The NDVI- and LAI-induced TVDI were both found to be negatively correlated with the SSM and precipitation. At some in situ sites improvements in the correlation between the dryness index, soil moisture and precipitation, were found when using the LAI-induced TVDI method which resulted in average correlation improvement. The spatial analysis between the dryness indices and ASCAT SSM using GWR showed the average negative correlation between those variables with high $\mathrm{R}$ values, which were improved for LAI-induced TVDI. Both dryness indices showed coherent spatial patterns with the remotely sensed soil moisture when vegetation was low and dry.

The study results suggest that the LAI-induced TVDI can be applied as a complement, or as an alternative to the conventional NDVI-induced TVDI. Further researches, specifically under high vegetation and wet conditions may be needed for broader use of dryness indices derived from $\mathrm{VI} / \mathrm{T}_{\mathrm{S}}$ space.

Acknowledgements We sincerely thank the Integrated Climate Data Centre (ICDC, http://icdc.zmaw.de), University of Hamburg, Hamburg, Germany, for providing "ASCAT Soil Moisture 2007 - 2013, Institute of Photogrammetry and Remote Sensing (IPF), Vienna Institute of Technology (TU Wien), Vienna, Austria, provided daily as moving 5-Day mean". Sincere thanks also to RDA for providing in situ soil moisture data in South Korea. This research was supported by the Space Core Technology Development Program through the National Research Foundation of Korea (NRF) funded by the Ministry of Science, ICT and Future Planning (NRF-2014M1A3A3A02034789).

\section{REFERENCES}

Albergel, C., C. Rüdiger, D. Carrer, J. C. Calvet, N. Fritz, V. Naeimi, Z. Bartalis, and S. Hasenauer, 2009: An evaluation of ASCAT surface soil moisture products with in-situ observations in Southwestern France. Hydrol. Earth Syst. Sci., 13, 115-124, doi: 10.5194/hess-13115-2009. [Link]

Baret, F. and G. Guyot, 1991: Potentials and limits of vegetation indices for LAI and APAR assessment. Remote Sens. Environ., 35, 161-173, doi: 10.1016/0034-4257(91)90009-U. [Link]

Boegh, E., H. Soegaard, N. Hanan, P. Kabat, and L. Lesch, 1999: A remote sensing study of the NDVI- $T_{s}$ relationship and the transpiration from sparse vegetation in the
Sahel based on high-resolution satellite data. Remote Sens. Environ., 69, 224-240, doi: 10.1016/S00344257(99)00025-5. [Link]

Brocca, L., F. Melone, T. Moramarco, W. Wagner, and S. Hasenauer, 2010: ASCAT soil wetness index validation through in situ and modeled soil moisture data in central Italy. Remote Sens. Environ., 114, 2745-2755, doi: 10.1016/j.rse.2010.06.009. [Link]

Brunsdon, C., A. S. Fotheringham, and M. E. Charlton, 1996: Geographically weighted regression: A method for exploring spatial nonstationarity. Geogr. Anal., 28, 281298, doi: 10.1111/j.1538-4632.1996.tb00936.x. [Link]

Carlà, R., K. Fontanelli, and L. Santurri, 2012: A Multitemporal Ts-VI (MTVI) method for surface soil moisture assessment at regional scale. $1^{\text {st }}$ EARSeL Workshop on Temporal Analysis of Satellite Images, Mykonos, Greece, 6 pp, doi: 10.13140/2.1.3653.3449. [Link]

Carlson, T. N. and D. A. Ripley, 1997: On the relation between NDVI, fractional vegetation cover, and leaf area index. Remote Sens. Environ., 62, 241-252, doi: 10.1016/S0034-4257(97)00104-1. [Link]

Chen, D. and W. Brutsaert, 1998: Satellite-sensed distribution and spatial patterns of vegetation parameters over a tallgrass prairie. J. Atmos. Sci., 55, 1225-1238, doi: 10 $.1175 / 1520-0469$ (1998)055<1225:SSDASP>2.0.CO;2. [Link]

Chen, J. M. and T. A. Black, 1992: Defining leaf area index for non-flat leaves. Plant Cell Environ., 15, 421-429, doi: 10.1111/j.1365-3040.1992.tb00992.x. [Link]

Cho, E., M. Choi, and W. Wagner, 2015: An assessment of remotely sensed surface and root zone soil moisture through active and passive sensors in northeast Asia. Remote Sens. Environ., 160, 166-179, doi: 10.1016/j. rse.2015.01.013. [Link]

Choi, M. and Y. Hur, 2012: A microwave-optical/infrared disaggregation for improving spatial representation of soil moisture using AMSR-E and MODIS products. Remote Sens. Environ., 124, 259-269, doi: 10.1016/j. rse.2012.05.009. [Link]

Choi, M., J. M. Jacobs, and D. D. Bosch, 2008: Remote sensing observatory validation of surface soil moisture using Advanced Microwave Scanning Radiometer E, Common Land Model, and ground based data: Case study in SMEX03 Little River Region, Georgia, U.S. Water resources research., 44, W08421, doi: 10.1029/2006WR005578. [Link]

Dorigo. W. A., W. Wagner, R. Hohensinn, S. Hahn, C. Paulik, A. Xaver, A. Gruber, M. Drusch, S. Mecklenburg, P. van Oevelen, A. Robock, and T. Jackson, 2011: The International Soil Moisture Network: A data hosting facility for global in situ soil moisture measurements. Hydrol. Earth Syst. Sci., 15, 1675-1698, doi: 10.5194/ hess-15-1675-2011. [Link]

Dubois, P. C., J. van Zyl, and T. Engman, 1995: Measuring 
soil moisture with imaging radars. IEEE Trans. Geosci. Remote Sensing, 33, 915-926, doi: 10.1109/36.406677. [Link]

Engman, E. T. and N. Chauhan, 1995: Status of microwave soil moisture measurements with remote sensing. Remote Sens. Environ., 51, 189-198, doi: 10.1016/00344257(94)00074-W. [Link]

Fensholt, R., I. Sandholt, and M. S. Rasmussen, 2004: Evaluation of MODIS LAI, fAPAR and the relation between AAPAR and NDVI in a semi-arid environment using in situ measurements. Remote Sens. Environ.,91, 490-507, doi: 10.1016/j.rse.2004.04.009. [Link]

Foody, G. M., 2003: Geographical weighting as a further refinement to regression modelling: An example focused on the NDVI-rainfall relationship. Remote Sens. Environ., 88, 283-293, doi: 10.1016/j.rse.2003.08.004. [Link]

Fotheringham, A. S., C. Brunsdon, and M. Charlton, 2002: Geographically Weighted Regression: The Analysis of Spatially Varying Relationships, Wiley, Chichester, $284 \mathrm{pp}$.

Goetz, S. J., 1997: Multi-sensor analysis of NDVI, surface temperature and biophysical variables at a mixed grassland site. Int. J. Remote Sens., 18, 71-94, doi: 10.1080/014311697219286. [Link]

Gu, Y., J. F. Brown, J. P. Verdin, and B. Wardlow, 2007: A five-year analysis of MODIS NDVI and NDWI for grassland drought assessment over the central Great Plains of the United States. Geophys. Res. Lett., 34, L06407, doi: 10.1029/2006GL029127. [Link]

Han, L., P. Wang, H. Yang, S. Liu, and J. Wang, 2006: Study on NDVI- $T_{\mathrm{s}}$ space by combining LAI and evapotranspiration. Sci. China Ser. D, 49, 747-754, doi: $10.1007 /$ s11430-006-0747-0. [Link]

Han, Y., Y. Wang, and Y. Zhao, 2010: Estimating soil moisture conditions of the greater changbai mountains by land surface temperature and NDVI. IEEE Trans. Geosci. Remote Sensing, 48, 2509-2515, doi: 10.1109/ TGRS.2010.2040830. [Link]

Hatfield, J. L., G. Asrar, and E. T. Kanemasu, 1984: Intercepted photosynthetically active radiation estimated by spectral reflectance. Remote Sens. Environ., 14, 65-75, doi: 10.1016/0034-4257(84)90008-7. [Link]

Hill, M. J., U. Senarath, A. Lee, M. Zeppel, J. M. Nightingale, R. J. Williams, and T. R. McVicar, 2006: Assessment of the MODIS LAI product for Australian ecosystems. Remote Sens. Environ., 101, 495-518, doi: 10.1016/j.rse.2006.01.010. [Link]

Huete, A., K. Didan, T. Miura, E. P. Rodriguez, X. Gao, and L. G. Ferreira, 2002: Overview of the radiometric and biophysical performance of the MODIS vegetation indices. Remote Sens. Environ., 83, 195-213, doi: 10.1579/0044-7447-32.8.502. [Link]

Hwang, K. and M. Choi, 2013: Seasonal trends of satellite- based evapotranspiration algorithms over a complex ecosystem in East Asia. Remote Sens. Environ., 137, 244-263, doi: 10.1016/j.rse.2013.06.006. [Link]

Jackson, R. D., S. B. Idso, R. J. Reginato, and P. J. Pinter Jr., 1981: Canopy temperature as a crop water stress indicator. Water Resour. Res., 17, 1133-1138, doi: 10.1029/WR017i004p01133. [Link]

Jackson, T. J., J. Schmugge, and E. T. Engman, 1996: Remote sensing applications to hydrology: Soil moisture. Hydrolog. Sci. J., 41, 517-530, doi: 10.1080/ 02626669609491523. [Link]

Jackson, T. J., M. H. Cosh, R. Bindlish, P. J. Starks, D. D. Bosch, M. Seyfried, D. C. Goodrich, M. S. Moran, and J. Du, 2010: Validation of Advanced Microwave Scanning Radiometer soil moisture products. IEEE Trans. Geosci. Remote Sensing, 48, 4256-4272, doi: 10.1109/ TGRS.2010.2051035. [Link]

Kang, S., S. W. Running, J. H. Lim, M. Zhao, C. R. Park, and R. Loehman, 2003: A regional phenology model for detecting onset of greenness in temperate mixed forests, Korea: An application of MODIS leaf area index. Remote Sens. Environ., 86, 232-242, doi: 10.1016/ S0034-4257(03)00103-2. [Link]

Knyazikhin, Y., J. V. Martonchik, R. B. Myneni, D. J. Diner, and S. W. Running, 1998: Synergistic algorithm for estimating vegetation canopy leaf area index and fraction of absorbed photosynthetically active radiation from MODIS and MISR data. J. Geophys. Res., 103, 32257-32275, doi: 10.1029/98JD02462. [Link]

Loew, A., 2008: Impact of surface heterogeneity on surface soil moisture retrievals from passive microwave data at the regional scale: The Upper Danube case. Remote Sens. Environ., 112, 231-248, doi: 10.1016/j. rse.2007.04.009. [Link]

Mallick, K., B. K. Bhattacharya, and N. K. Patel, 2009: Estimating volumetric surface moisture content for cropped soils using a soil wetness index based on surface temperature and NDVI. Agric. For. Meteorol., 149, $1327-$ 1342, doi: 10.1016/j.agrformet.2009.03.004. [Link]

Masuoka, E., A. Fleig, R. E. Wolfe, and F. Patt, 1998: Key characteristics of MODIS data products. IEEE Trans. Geosci. Remote Sensing, 36, 1313-1323, doi: 10.1109/36.701081. [Link]

Moran, M. S., T. R. Clarke, Y. Inoue, and A. Vidal, 1994: Estimating crop water deficit using the relation between surface-air temperature and spectral vegetation index. Remote Sens. Environ., 49, 246-263, doi: 10.1016/0034-4257(94)90020-5. [Link]

Njoku, E. G. and D. Entekhabi, 1996: Passive microwave remote sensing of soil moisture. J. Hydrol., 184, 101129, doi: 10.1016/0022-1694(95)02970-2. [Link]

Patel, N. R., R. Anapashsha, S. Kumar, S. K. Saha, and V. K. Dadhwal, 2009: Assessing potential of MODIS derived temperature/vegetation condition index (TVDI) 
to infer soil moisture status. Int. J. Remote Sens., $\mathbf{3 0}$, 23-39, doi: 10.1080/01431160802108497. [Link]

Price, J. C., 1990: Using spatial context in satellite data to infer regional scale evapotranspiration. IEEE Trans. Geosci. Remote Sensing, 28, 940-948, doi: 10.1109/36.58983. [Link]

Rahimzadeh-Bajgiran, P., K. Omasa, and Y. Shimizu, 2012: Comparative evaluation of the Vegetation Dryness Index (VDI), the Temperature Vegetation Dryness Index (TVDI) and the improved TVDI (iTVDI) for water stress detection in semi-arid regions of Iran. ISPRS J. Photogramm., 68, 1-12, doi: 10.1016/j. isprsjprs.2011.10.009. [Link]

Salomonson, V. V., W. Barnes, J. Xiong, S. Kempler, and E. Masuoka, 2002: An overview of the Earth Observing System MODIS instrument and associated data systems performance. IEEE Trans. Geosci. Remote Sensing, 2, 1174-1176, doi: 10.1109/IGARSS .2002.1025812. [Link]

Sandholt, I., K. Rasmussen, and J. Andersen, 2002: A simple interpretation of the surface temperature/vegetation index space for assessment of surface moisture status. Remote Sens. Environ., 79, 213-224, doi: 10.1016/ S0034-4257(01)00274-7. [Link]
Shin, Y. and B. P. Mohanty, 2013: Development of a deterministic downscaling algorithm for remote sensing soil moisture footprint using soil and vegetation classifications. Water Resour. Res., 49, 6208-6228, doi: 10.1002/wrcr.20495. [Link]

Verspeek, J., A. Stoffelen, M. Portabella, H. Bonekamp, C. Anderson, and J. F. Saldaña, 2010: Validation and calibration of ASCAT using CMOD5.n. IEEE Trans. Geosci. Remote Sensing, 48, 386-395, doi: 10.1109/ TGRS.2009.2027896. [Link]

Wan, Z. and J. Dozier, 1996: A generalized split-window algorithm for retrieving land-surface temperature from space. IEEE Trans. Geosci. Remote Sensing, 34, 892905, doi: 10.1109/36.508406. [Link]

Wan, Z., Y. Zhang, Q. Zhang, and Z. L. Li, 2004: Quality assessment and validation of the MODIS global land surface temperature. Int. J. Remote Sens., 25, 261-274, doi: 10.1080/0143116031000116417. [Link]

Wang, Y., C. E. Woodcock, W. Buermann, P. Stenberg, P. Voipio, H. Smolander, T. Häme, Y. Tian, J. Hu, Y. Knyazikhin, and R. B. Myneni, 2004: Evaluation of the MODIS LAI algorithm at a coniferous forest site in Finland. Remote Sens. Environ., 91, 114-127, doi: 10.1016/j.rse.2004.02.007. [Link] 